\title{
Analysis of Provincial Energy Consumption and Carbon Emissions Effect of West-to-East Gas Transmission Project: Based on PSM-DID Method
}

\section{Xiaomei LUAN}

Hubei University of Education

Danny Chunying Cui ( $24840079 @ q q . c o m$ )

Wenhua College

Dianping Zhang

Wenhua College

Junyue XIE

Wuxi Branch of China Post Corporation

\section{Ziwei YAN}

Wenhua College

\section{Research Article}

Keywords: West-to-East gas transmission project, energy conservation and emissions reduction, Propensity Score Matching Differences-in-Differences

Posted Date: August 13th, 2021

DOI: https://doi.org/10.21203/rs.3.rs-759337/v1

License: (c) (i) This work is licensed under a Creative Commons Attribution 4.0 International License. Read Full License 


\section{Abstract}

West-to-East gas transmission project (WEGTP) is a major energy construction programm in China. Evaluating its impacts on the energy consumption and carbon emissions(ECER) in involved provinces is of great significance for further achieve the goals of high-quality development. This paper takes WEGTP as a quasi-natural experiment, calculates the total energy consumption and carbon emissions by employing the provincial panel data of 1997-2017, and applies a counterfactual framework under Rubin Causal Model (RCM) to estimate the ECER policy effect of WEGTP Line I Subproject. It is found that WEGTP generates an overall carbon emissions reduction effect in the involved provinces. Further heterogeneity analysis points out that the project has an obvious energy conservation effect on the natural gas importer provinces, however the emissions reduction effect is not significant, while the project has significant positive effects on energy conservation and emissions reduction in the natural gas exporter provinces. Based on the results, WEGTP has played a long-term role in promoting energy structure optimization and carbon emissions reduction. It is still necessary to figure out the price mechanism of natural gas consumption, actively promote the structure of industrial, and meet the objective requirements of high-quality development with the actual effects of energy conservation and emissions reduction.

\section{Introduction}

Since the beginning of the 21 st century, global warming caused by $\mathrm{CO}_{2}$ emissions has posed a enormous challenge to human survival and development. Energy conservation and emissions reduction have always been a focus of China transforming its economic growth model and an objective requirement for realizing the UN Millennium Development Goals. Reducing energy consumption and $\mathrm{CO}_{2}$ emissions has become an inevitable trend of China's economic and social development.

Compared with coal, which has long dominated energy consumption in China, natural gas is characterized by less combustion emission and higher energy efficiency, as a kind of less polluting energy. Western China has abundant natural gas resources, while eastern China faces huge total energy consumption volume. The West-to-East gas transmission project (WEGTP) just delivers natural gas from western China to eastern regions like Shanghai and the Yangtze River Delta, to meet the growing demand for low-pollution energy in these provinces. This project is implemented to achieve the purpose of decrease emissions of pollutants such as $\mathrm{CO}_{2}$ by replacing coal with natural gas, which has low carbon emission and high thermal efficiency. WEGTP Line I Subproject connects ten provinces, completed and put into use at the end of 2004; Line II Subproject was completed in 2012, and Line II Subproject (West Line) was completed in 2017. Hence, WEGTP established natural gas pipelines with the longest distance, the largest pipe diameter, the most investment, the largest gas transmission rate, and the most complex construction conditions in China. It is hoped that this project can not only solve the energy shortage problem in the eastern region, but also advance the optimization of energy structure, promote energy conservation and emissions reduction, and effectively control air pollution in the provinces concerned. 
So far, WEGTP has been put into use for years. How much has it on earth improved China's energy consumption and carbon emission? Empirical analysis of this issue is rare. Therefore, this paper takes the completion for the above issue.The study adopts a Propensity Score Matching Differences-inDifferences(PSM-DID) method, and suppose WEGTP as the policy intervention to provide empirical evidence.

The possible marginal contributions of this paper are: 1) Taking WEGTP as a quasi-natural experiment, observing the changes of provincial energy consumption and carbon emissions, enriched the research achievements about the energy transportation pattern of China; 2 ) using RCM to evaluate the ECER efficiency of WEGTP as a new attempt in this field.

There are already fruitful research achievements on the ECER effects of WEGTP. They can be divided into three types according to different research fields: 1) natural gas substitution effect and ECER effect of WEGTP; 2) estimation of carbon emission in WEGTP related provinces; 3 ) analysis of factors affecting carbon emission.

A pool of theoretical results and analytical tools has been accumulated in the research field of influence of WEGTP and other industries. The primary view is that the extensive use of natural gas in place of coal can reduce total pollutant emissions and improve air quality(Xue $J$ et al.,2012;Pang J囚2015). The research is still scarce on how WEGTP realizes energy substitution $\square$ and how effective WEGTP is in the process of ECER.

In the field of carbon emission estimation, the academic circle universally adopts the method of atomic weight conversion. The intensity of carbon emission is estimated by Logarithmic Mean Divisia Index, and many scholars believe that energy intensity is the fundamental factor of reducing carbon emissions( Lin B Q, Jiang Z J,2009; Sun Z R, Zhou D Q et al., 2015). According to estimates, the energy consumption efficiency and carbon emission efficiency in eastern China are significantly higher than those in central and western regions(Xu S C, Long R Y, 2015). Other studies use Kaya identity to decompose the factors of carbon emission intensity(Liu G W, Zhao T, 2012).

The analysis of the influencing factors of carbon emissions has generated a large pool of results. The literature points out that the total economic output and energy consumption efficiency are the key factors that determine the overall level of carbon emissions(Song D Y, Lu Z B, 2009), so that energy-saving technology, economic scale, industrial structure, and energy consumption structure have significant negative impacts on carbon emission efficiency(Wu J, Cui C, Mei X, et al., 2021). However, some scholars have pointed out that the per capita output level and the optimization of industrial structure have significant positive effects on carbon emission intensity(Cui H R, 2019). From the perspective of dynamic incremental, Zhang Qingyu et al.(2019) verified that GDP increase is the main factor affecting China's total carbon emissions.

In addition, the causal inference of policy effect that reflects experimental measurement ideas has become a hot subject in the carbon emission field in recent years. Rising oil price, rail transit construction, 
low-carbon city pilot projects and energy substitution policies have been studied with a differences-indifferences (DID) method as policy variables(Xi P H et al., 2015; Liang R B et al.,2016; Tang Y et al.,2018; Dai R, Cao J H, 2015 ). Empirical metrology emphasizes the ergodicity of potential results. It takes policy shock as the core explanatory variable, and uses the counterfactual approach to analyze the causal effect brought by policies, providing a powerful tool for studying the actual impacts of ECER policies.

Throughout the above research, the existing literatures mainly focuses on the mutual impacts between WEGTP and natural gas and other industries. Fruitful theoretical results and empirical conclusions have been accumulated in these aspects. However, no quantitative research on the impact of WEGTP on the carbon emissions in the provinces concerned has not been reported yet, possibly because it is difficult to acquire the specific data on the actual energy consumption in each province. That is why studies on WEGTP generally choose other aspects with direct outcome indicators. In addition, studies of traditional statistical measurement generally focus on estimation and comparison of historical data in provinces concerned before and after the supply of natural gas. Therefore, although the above studies are in large quantities, they are not varying in tools and methods, and hardly carry out independent causal inference on the policy effect of WEGTP. This urges us to apply PSM-DID to study the ECER effects of WEGTP.

\section{Methodology}

\subsection{Data sources and calculation}

The explained variable needed by this study is $\mathrm{CO}_{2}$ emission, the data of which is not published at present, so this paper acquires the energy consumption data of each province and conducts calculations with the energy emission calculation method stipulated in IPCC 2006 standard. First, the total actual consumption of each type of energy of each province in each year is collected; second, energy consumption conversion is conducted according to the standard coal conversion coefficient listed in the corresponding table; finally, estimation is conducted according to the product of the chemical carbon emission coefficients of various energies, and the atomic mass conversion of standard carbon atom emission and $\mathrm{CO}_{2}$ emission (see Table 1 ) is carried out. The formula is as follows:

$$
\mathrm{CO}_{2}=\sum_{i=1}^{8} E_{\mathrm{t}} \times S_{t} \times N_{\mathrm{t}} \times 44 / 12
$$

$\mathrm{CO}_{2}$ represents the output variable- $\mathrm{CO}_{2}$ emission; Et represents the consumption of Category $\mathrm{t}$ fossil fuel; St represents the standard coal conversion coefficient of Category $t$ fossil fuel; $\mathrm{Nt}$ represents the carbon emission coefficient of Category $\mathrm{t}$ fossil fuel; $44 / 12$ represents the ratio of $\mathrm{CO}_{2}$ to $\mathrm{C}$ molecules. The original data of eight kinds of fossil fuels is collated and multiplied by the coefficient of standard coal conversion. The carbon emission coefficient of each kind of fossil fuel before the eight kinds of fossil fuels are added together and multiplied by $44 / 12$ to get the total $\mathrm{CO}_{2}$ emissions. 
Table 1 Standard coal conversion coefficient and carbon emission of primary energies

\begin{tabular}{|c|c|c|c|c|c|c|c|c|}
\hline Energy type & Coal & Coke & Crude & Gasoline & Kerosene & Diesel & $\begin{array}{l}\text { Fuel } \\
\text { oil }\end{array}$ & $\begin{array}{l}\text { Natural } \\
\text { gas }\end{array}$ \\
\hline $\begin{array}{l}\text { Convert standard coal } \\
\text { coefficient } ₫ \text { tce } / \mathrm{t} \rrbracket\end{array}$ & 0.71 & 0.97 & 1.43 & 1.47 & 1.47 & 1.46 & 1.43 & 1.33 \\
\hline $\begin{array}{l}\text { Carbon emission } \\
\text { coefficient }(t C / \text { tce })\end{array}$ & 0.76 & 0.86 & 0.59 & 0.59 & 0.57 & 0.59 & 0.62 & 0.45 \\
\hline
\end{tabular}

The data on the actual consumption of each kind of energy and the total primary energy consumption of each province were collected from China Energy Statistical Yearbook (1997-2017). Year-end resident population, fiscal income and GDP needed by government intervention, the output value of the secondary industry needed by industrial structure, average GDP, R\&D investment, per capita disposable income and other data are all taken from China Macro Economy Database. The above data receives logarithmic processing or conversion to form auxiliary variables.

\subsection{Sample selection}

WEGTP Line I Subproject runs across China from the west to the east and was put into use at the end of 2004. The ten provinces (Shanghai, Jiangsu, Zhejiang, Anhui, Henan, Ningxia, Xinjiang, Gansu, Shaanxi, Shanxi) involved in WEGTP constitute the treatment group of this study. The remaining twenty provinces constitute the control group (Tibet is excluded due to absence of historical data). Among the ten provinces, some are energy exporter provinces and others are energy importer provinces. Therefore, this paper not only studies the provinces as a whole, but also discusses the heterogeneity characteristics of energy exporter provinces and energy importer provinces respectively. Based on the primary energy consumption and production data estimates of all provinces in China from 1998 to 2017, Shanxi, Inner Mongolia, Heilongjiang, Guizhou, Xinjiang, Qinghai, Ningxia and Shaanxi are judged as energy exporter provinces.

The window phase of the WEGTP Line I Subproject is set as 2005-2012, because before the opening of Line I Subproject, domestic provinces had not used natural gas on a large scale, and the follow-up Line II Subproject and Line II (West Line) Subproject were not completed until 2017. This ensures that the 9 provinces involved in Line I Subproject have no overflow effect in policy intervention. By contrast, the projects after the opening of the Line I Subproject cannot avoid the diffusion of policy effect before completion.

\subsection{Specification of the measurement model}

This paper uses PSM-DID to estimate the ECER effect of WEGTP under conditions including unobserved variables. Since energy consumption and carbon emission vary greatly among Chinese provinces, a basic 
DID method can hardly avoid heterogeneity among provinces. To overcome the endogenous problems of DID囚such as bias of sample selection, this paper uses Propensity Score Matching (PSM) for the sample matching preprocessing of the DID (PSM-DID). The matching idea of PSM is to find out the sample provinces with the most similar conditions except natural gas supply from the control group, remove the observed values that do not meet the common trend assumption, form a new sample treatment group, and solve the selection bias of the treatment group through balance test. PSM can give the weight of all the indicators comprehensively in the treatment group, and DID estimation is conducted to the obtained matching results in contrast with the treatment group, which can effectively explain the net impacts of WEGTP on energy consumption and carbon emissions in involved provinces. According to the analytical steps of PSM-DID, this paper adopts the Logit method to complete propensity score, which matches the control group estimator formed by non-involved provinces with the treatment group formed by the involved provinces of WEGTP with PSM method, and constructs a counterfactual estimation. A DID model of kernel matching is then selected for a comparative study.

To sum up, the overall DID model is as follows:

$$
\begin{aligned}
& \ln T Q C_{i t}=\beta_{0}+\beta_{1} T_{\mathrm{it}}+\beta_{2} D_{\mathrm{it}}+\beta_{3} T_{t} \times D_{\mathrm{i}}+\beta_{4} \ln T P_{i t}+\beta_{5} G I_{i t}+\beta_{6} I S_{\mathrm{it}} \\
& +\beta_{7} \ln A G D P_{i t}+\beta_{8} \ln R D_{\mathrm{it}}+\beta_{9} \ln P C D I_{\text {it }}+\varepsilon_{\text {it }}
\end{aligned}
$$

In Formula (2), the dummy variables of province in period meet the following settings: is a time dummy variable ( $=1$ indicates a year after policy implementation, and $=0$ indicates a year before policy implementation); is a policy dummy variable ( $=1$ indicates a province involved in WEGTP, and $=0$ indicates a province not involved in WEGTP); is the DID estimator of the interaction item, that is, the effects of the opening of WEGTP on $\mathrm{CO}_{2}$ emissions. As a core explanatory variable, the coefficient of DID - - is the focus of this paper. is the logarithmic form of the explained variable- $\mathrm{CO}_{2}$, indicates the $\mathrm{CO}_{2}$ emission level of province in year, and is a random disturbance term.

In this paper, the auxiliary variables are selected according to the IPAT equation proposed by Erlich and Holdrenti (1971).

Suppose I=PAT, the environment variable I corresponds to the explained variables provincial energy consumption $(P E C)$ and total quantity of $\mathrm{CO}_{2}$ emission $(T Q C)$, the population factor $\mathrm{P}$ corresponds to the year-end resident population TP, the rich level A corresponds to average GDP (AGDP) and per capita disposable income $(A C D D)$, the technology level T corresponds to $\mathrm{R} \& \mathrm{D}$ investment $(R D)$. In addition, considering that the government's economic intervention capacity also plays a significant role in total energy consumption and carbon emissions, GF- the proportion of fiscal revenue in GDP-is included as an auxiliary variable; considering the proportion of industrial manufacturing has a reasonable impact on local energy consumption structure and carbon emissions, the rate of industrialization (the proportion of the secondary industry output value in regional GDP)-- $I S$ is adopted as the index of industrial structure.

The step-by-step model building is as follows: 
Formula (3) is the regression equation of Model 1. It is visible that no control variable is added. It is used to study the net impact of WEGTP on $\mathrm{CO} 2$ emissions.

$$
\ln T Q C_{i t}=\beta_{0}+\beta_{1} T_{t}+\beta_{2} D_{i}+\beta_{3} T_{t} \times D_{i}+\beta_{4} X_{i t}+\varepsilon_{i t}
$$

In Formula (4), $X_{i t}$ represents all the control variables. In order to divide the roles of the auxiliary variables clearly, this paper adopts the method of step-by-step substitution to successfully substitute the six control variables in Formula (1) into the formula for DID.

\subsection{Balance test}

A quasi-natural experiment must ensure the random allocation of the treatment group and the control group. This paper performs PSM before regression to find out the non-involved provinces that are as similar to the provinces involved in WEGTP as possible, in order to eliminate the selection bias of samples to the greatest extent. Figure 2(a) and (b) shows the kernel density distribution diagrams before and after PSM. By comparing between the two diagrams, a distinct gap can be found between involved provinces and non-involved provinces before PSM. After PSM, however, the involved provinces and the non-involved provinces show almost the same trends, a greater overlapping part and closer data distribution. The feature proves that the PSM results are ideal. Figure 2(c) is a common value range map of PSM. We can see that the propensity score ranges of the treatment group and the control group are totally the same, indicating that only a small amount of data is unmatched, hence the data selected in this paper meets the precondition of a common support domain. Figure 2(d) shows the standardized deviation map of each variable, which shows that the matched data eliminates most selection bias.

\section{Discussion Of Findings}

\subsection{Benchmark regression}

In this paper, distribution regression is adopted to obtain the DID results with Intq and Inpec as explained variables to analyze the effects of WEGTP on $\mathrm{CO}_{2}$ emissions. Table 2 shows seven models, whose construction is already shown above. Model 1 is derived from Formula (1) when there are only three dummy variables: policy point $T$, treatment group $D$, and policy effect, namely, the interaction item . The results in Table (2) show the net impact of WEGTP when no control variable is added. The coefficient of the interaction item is negative, but the significance of the net impact does not meet the standard of $1 \%$ to $10 \%$. It indicates that the model without any control variable cannot explain $\mathrm{CO}_{2}$ emissions sufficiently. Therefore, control variables must be added on that basis in order to observe the performance. "Year-end resident population" is added to Model 2. The coefficient of the interaction item is negative just like 
Model 1, but the $10 \%$ level of significance test is failed. After the new control variable "government intervention" is added to Model 3 , the $10 \%$ level of significance test is passed, and the coefficient of the interaction item is still negative. After the addition of control variables population and government intervention, Model 3 can better explain the explained variable. The coefficients of population and government intervention are both positive and significant, indicating that the increase in population has caused an increase in total $\mathrm{CO}_{2}$ emissions. Each person increased leads to 0.761 units of carbon emissions to meet the needs of industry, transportation and so on in daily life. Each unit GDP of fiscal revenue increase leads to 0.761 units of carbon emissions.

Table 2 PSM-DID estimation of carbon dioxide emissions 


\begin{tabular}{|c|c|c|c|c|c|c|c|}
\hline Variables & Model 1 & Model 2 & Model 3 & Model 4 & Model 5 & Model 6 & Model 7 \\
\hline \multirow[t]{2}{*}{$T$} & $0.629 * * *$ & $0.621 * * *$ & $0.551 * * *$ & $0.427 * \star \star$ & $0.261^{\star * \star}$ & $0.253^{* * *}$ & $0.414 * \star \star$ \\
\hline & (8.290) & (13.620) & $(12.160)$ & (10.220) & (5.580) & $(5.420)$ & (7.920) \\
\hline \multirow[t]{4}{*}{$D$} & -0.001 & $0.097^{\star}$ & $0.108^{\star \star}$ & 0.024 & 0.042 & 0.065 & $0.076^{*}$ \\
\hline & $(-0.010)$ & $(1.740)$ & $(2.020)$ & $(0.490)$ & $(0.900)$ & $(1.400)$ & $(1.700)$ \\
\hline & -0.046 & -0.090 & $-0.126^{\star}$ & -0.134 ** & $-0.115^{\star \star}$ & -0.120 ** & $-0.111^{\star \star \star}$ \\
\hline & $(-0.350)$ & $(-1.150)$ & $(-1.660)$ & $(-1.990)$ & $(-1.780)$ & $(-1.880)$ & $(-1.800)$ \\
\hline \multirow[t]{2}{*}{ LNTP } & & $0.711^{\star * *}$ & $0.761 * \star \star *$ & $0.736 * \star \star *$ & $0.727 * \star \star *$ & $0.808 * \star \star *$ & $0.911 * \star \star$ \\
\hline & & $(28.430)$ & $(29.950)$ & (32.430) & (33.550) & (22.690) & (23.770) \\
\hline \multirow[t]{2}{*}{ Gl } & & & $4.302^{\star \star *}$ & $6.099 * * *$ & $2.535^{\star \star \star}$ & $2.857 * \star \star$ & $4.757 * \star \star *$ \\
\hline & & & (6.100) & (9.430) & (3.120) & (3.510) & (5.620) \\
\hline \multirow[t]{2}{*}{ IS } & & & & $3.025^{\star \star \star}$ & 1.964 *** & $1.895^{\star \star \star}$ & $1.529 * \star \star$ \\
\hline & & & & (11.030) & $(6.430)$ & $(6.230)$ & $(5.110)$ \\
\hline \multirow[t]{2}{*}{$\angle N A G D P$} & & & & & $0.234 * * \star$ & $0.332^{\star \star *}$ & $0.745^{\star \star \star}$ \\
\hline & & & & & $(6.740)$ & $(6.810)$ & $(8.950)$ \\
\hline \multirow[t]{2}{*}{$L N R D$} & & & & & & $-0.075^{\star \star \star}$ & 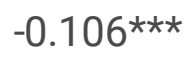 \\
\hline & & & & & & $-2.840)$ & $(-4.070)$ \\
\hline \multirow[t]{2}{*}{ LNACDI } & & & & & & & 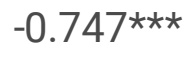 \\
\hline & & & & & & & $(-6.010)$ \\
\hline \multirow[t]{2}{*}{ F-test } & 32.780 & 270.730 & 241.380 & 275.180 & 265.550 & 237.020 & 231.190 \\
\hline & $(0.000)$ & $(0.000)$ & $(0.000)$ & $(0.000)$ & $(0.000)$ & $(0.000)$ & $(0.000)$ \\
\hline Adjust $R^{2}$ & 0.172 & 0.703 & 0.725 & 0.783 & 0.802 & 0.805 & 0.819 \\
\hline
\end{tabular}

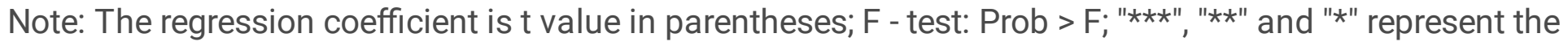
significance level of $1 \%, 5 \%$ and $10 \%$ respectively.

IS (industrial structure) is added to Model 4 on the basis of Model 3. The coefficient of the interaction item is the same as the expectation and the negative value is smaller, indicating that $\mathrm{CO}_{2}$ emissions still show a downward trend. As a result, the $5 \%$ significance level test is passed. The value of adjusted $\mathrm{R}^{2}$ (coefficient of determination) is 0.783 , up by 0.05 points on the basis of Model 3 . Moreover, the secondary industry ratio coefficient is 3.025, indicating a very significant positive effect on total $\mathrm{CO}_{2}$ emissions. Due to the different industrial departments, the structure and types of energy consumption are also different. The secondary industry mainly refers to the processing and manufacturing industries. 
Compared with the primary industry and the tertiary industry, the secondary industry has higher requirements for energy consumption and a higher carbon emission coefficient in production and life. The increased amplitude of $\mathrm{CO} 2$ emissions is smaller than that of production output, $\mathrm{so}^{\mathrm{CO}} \mathrm{O}_{2}$ emissions increase.

Average GDP reflects the affluence of the people of a country, and AGDP is added to Model 5 on the basis of Model 4 . The coefficient is -0.115 , passing the level of significance test. The value of adjusted $R^{2}$ (coefficient of determination) is 0.802 , and the AGDP coefficient becomes 0.234 , indicating that AGDP has a positive effect on $\mathrm{CO}_{2}$ emissions. The reason is that when AGDP increases, energy consumption also increases with improved living standards. When the actual energy consumption becomes bigger, and the standard coal conversion coefficient and carbon emission coefficient remain unchanged, the total $\mathrm{CO}_{2}$ emissions become bigger. After the interaction item of "R\&D investment" is added to Model 6 on the basis of Model 5 , the coefficient becomes -0.120 , which once again proves the emissions reduction effect of WEGTP. The improvement of technology level is largely determined by investment in research and development. The improvement of technology level has both positive and negative effects on $\mathrm{CO}_{2}$ emissions: on the one hand, it drives economic growth, thus increasing energy consumption and $\mathrm{CO}_{2}$ emissions; on the other hand, it improves energy utilization efficiency and optimizes energy structure, thus reducing $\mathrm{CO}_{2}$ emissions. According to the table, when the value of adjusted $\mathrm{R}^{2}$ (coefficient of determination) is adjusted to 0.805 , the coefficient of $R \& D$ investment is -0.075 , indicating a negative effect of $\mathrm{R} \& \mathrm{D}$ investment on $\mathrm{CO}_{2}$ emissions. This result is consistent with the theoretical possibility of reducing $\mathrm{CO}_{2}$ emissions. Increased $\mathrm{R} \& \mathrm{D}$ investment promotes technological progress. In the past 10 to 20 years, China's scientific research units, taking into account market demand, have increased research and development in ECER and achieved considerable achievements. People use high-level production tools in daily life, or industrial production, or technological improvements lead to the optimization of energy structure, thus reducing $\mathrm{CO}_{2}$ emissions.

Model 7 puts together six control variables, with per capita disposable income newly added on the basis of Model 6 The value of the interaction item becomes -0.111 , and the result is significant. Throughout the above process, the regression coefficient of PSM-DID remains negative, indicating that the conclusion "WEGTP reduces $\mathrm{CO}_{2}$ emissions" is stable after adding the control variables. From the table, we can see that per capita disposable income reduces $\mathrm{CO}_{2}$ emissions, possibly because the increase of ACDI enhances purchasing power, so that people have a more solid material basis to improve consumption structure-- they become more willing to use clean energy like natural gas, thus increasing the demand for clean energy and contributing to carbon emissions reduction.

\subsection{Heterogeneity test}

For energy importer provinces and energy exporter provinces, the impacts of WEGTP on energy consumption and carbon emissions are different. In energy importer provinces, the supply of natural gas 
increases total energy consumption, but changes in the total quantity and intensity of carbon emissions are uncertain. In energy exporter provinces, natural gas takes a substitution effect, the primary energy consumption structure sees a substantial reduction in the proportion of coal, and there should be a significant decline in carbon emissions. According to the above characteristics, the paper will next conduct a heterogeneity test on the energy importer provinces and the energy exporter provinces in the treatment group.

Table 3 Estimates of energy consumption in import provinces

\begin{tabular}{|c|c|c|c|c|}
\hline \multirow[t]{2}{*}{ Variables } & \multicolumn{4}{|c|}{ Energy consumption in imported provinces } \\
\hline & Model 8 & Model 9 & Model 10 & Model 11 \\
\hline & $-0.071 * \star *$ & 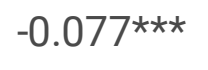 & $-0.066^{* \star *}$ & $-0.065^{\star \star \star}$ \\
\hline & $(-3.150)$ & $(-3.510)$ & $(-2.960)$ & $(-2.860)$ \\
\hline \multirow[t]{2}{*}{ LNTP } & & $0.423^{\star \star \star}$ & $0.478 * \star \star$ & $0.489 * \star \star$ \\
\hline & & (3.830) & $(4.250)$ & $(4.260)$ \\
\hline \multirow[t]{2}{*}{ GI } & & & $-1.351^{\star \star \star}$ & $-1.324 * \star \star$ \\
\hline & & & $(-2.220)$ & $(-2.170)$ \\
\hline \multirow[t]{2}{*}{ IS } & & & & 0.110 \\
\hline & & & & $(0.500)$ \\
\hline \multirow[t]{2}{*}{ LNAGDP } & $0.319 * \star \star$ & $0.459 * \star \star$ & $0.468 * \star \star$ & $0.448^{* \star *}$ \\
\hline & (4.920) & $(6.280)$ & $(6.480)$ & $(5.380)$ \\
\hline \multirow[t]{2}{*}{ F-test } & 378.57 & 375.800 & 361.310 & 342.330 \\
\hline & $(0.000)$ & $(0.000)$ & $(0.000)$ & $(0.000)$ \\
\hline Adjust $R^{2}$ & 0.958 & 0.960 & 0.961 & 0.961 \\
\hline
\end{tabular}

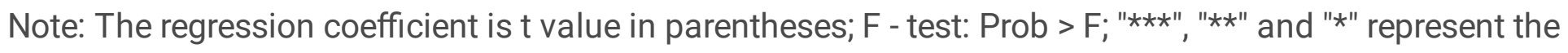
significance level of $1 \%, 5 \%$ and $10 \%$ respectively.

This paper still adopts the abovementioned method of substituting control variables step by step. According to the regression results of four models on the energy consumption of importer provinces, as shown in Table 3, the interaction items of the four models are all negative at a significance level under $10 \%$. The coefficient of interaction item of Model 8 is negative, indicating that WEGTP brings a downward trend to energy consumption in the importer provinces. However, the AGDP coefficient is positive, probably because the importer provinces are mostly located in the eastern coastal areas which were densely populated. With the increase of per capita income of residents, the narrowing gap between urban areas and rural areas and the realization of common prosperity, and the overall balanced and coordinated 
local development, the energy consumption levels of urban and rural residents began to rise, gradually raising the total energy consumption of local society as a whole. Year-end resident population, government intervention, and industrial structure are added to Model 9, Model 10 and Model 4 respectively. It can be seen that the interaction item result and control variables in Model 9 and Model 10 are significant, indicating that energy consumption was reduced in importer provinces after the opening of WEGTP. Although the interaction item is negative and significant after the addition of industrial structure to Model 11, the impact of industrial structure alone is not significant. The reason may be that although the proportion of the secondary industry in GDP is gradually declining, the industrial sector itself is a large energy consumer, and that WEGTP has a structural substitution effect on industrial energy consumption, however the energy conservation effect is subject to technical conditions. The manufacturing sectors of the eastern importer provinces undertake a large amount of export commodity production, and there is a trend that high energy consumption commodities are produced domestically and then exported to foreign countries.

Table 4 Heterogeneity analysis of energy export provinces

\begin{tabular}{lll} 
Variables & Emission of $\mathrm{CO}_{2}(\mathrm{InTQ})$ & Energy consumption(InPEC) \\
\hline & $-0.154^{\star \star}$ & $-0.111^{\star}$ \\
& $(-1.820)$ & $(-1.740)$ \\
\hline LNTP & $0.884^{\star \star \star}$ & $0.964^{\star \star \star}$ \\
& $(19.100)$ & $(27.550)$ \\
\hline GI & $3.068^{\star \star \star}$ & $3.906^{\star \star \star}$ \\
& $(2.840)$ & $(4.780)$ \\
\hline IS & $1.866^{\star \star \star}$ & $1.677^{\star \star \star}$ \\
& $(4.740)$ & $(5.630)$ \\
\hline LNAGDP & $0.566^{\star \star \star}$ & $0.888^{\star \star \star}$ \\
& $(5.720)$ & $(11.86)$ \\
\hline LNACDI & $-0.437 \star \star \star$ & $-0.755^{\star \star \star}$ \\
& $(-2.570)$ & $(-5.880)$ \\
\hline F-test & 161.340 & 329.400 \\
& $(0.000)$ & $(0.000)$
\end{tabular}

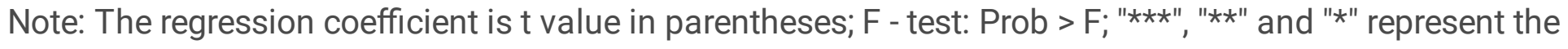
significance level of $1 \%, 5 \%$ and $10 \%$ respectively. 
This paper discusses the heterogeneity of energy exporter provinces from the two explained variables of $\mathrm{CO}_{2}$ emission and energy consumption. It can be seen from Table 4 that when $\mathrm{CO}_{2}$ emission is used as an explained variable of energy exporter provinces, the coefficient of interaction item is -0.154 . The significance test is passed, and the adjusted $\mathrm{R}^{2}$ is 0.797 , indicating that $\mathrm{CO} 2$ emissions are reduced in energy exporter provinces under. The reason may be that China's primary energy structure is dominated by coal. After the comprehensive operation of WEGTP, coal became uneconomical in terms of price and thermal efficiency, while natural gas is superior in price, thermal efficiency and carbon emissions. Coal consumption in the market, subject to the government's ECER targets stipulated by the 11th Five-Year Plan and the 12th Five-Year Plan, was first replaced. In the same period, many northern provinces gradually replaced coal with natural gas to fuel urban central heating boilers, which also directly reduced $\mathrm{CO}_{2}$ emissions in winter. When energy consumption is used as the explained variable of energy exporter provinces, the coefficient of interaction item is still negative at the significance level, and the adjusted $\mathrm{R}^{2}$ is 0.889 , indicating that the energy consumption in exporter provinces was declining, which is consistent with the $\mathrm{CO}_{2}$ emission results obtained above.

\subsection{Robustness test}

In order to prove the credibility of the above PSM-DID regression results, this paper provides a robustness test on the above regression results through a randomness test of policy intervention time, a test of the control group's immunity to policy, and a test of policy implementation uniqueness listed in Table 5.

\section{Randomness test of policy intervention time}

First, a randomness test of policy intervention time was conducted. The settings of the treatment group and the control group kept unchanged, the time node of policy intervention was advanced to 2001. It can be seen from table 5 that the interaction item result is not significant, indicating that $\mathrm{CO}_{2}$ emissions did not decrease significantly in 2001. Similarly, the time node was advanced to 2000 . Then, the interaction item result is still not significant. To sum up, the policy intervention time is random.

\section{Placebo test of the policy treatment}

By supposing a place that is not affected by the policy as a placebo sample, to estimate the treatment of hypothetical policy as if WEGTP accessed in there. That is, when the time node of policy intervention is kept unchanged, provinces are randomly selected from the original control group as the treatment group to observe whether the coefficient of interaction item is significant. If it is significant, it indicates that the control group is affected by policy, and the test is failed; if not, it indicates that the control group is not affected by policy, and the test is passed. It can be seen from Table 5 that the coefficient of interaction item is not significant, so the selection of the control group passed the test.

3. Test of policy implementation uniqueness 
WEGTP was opened roughly at the end of 2004. In the same period, in addition to the policy of WEGTP, the Great Western Development Strategy was also underway. It is one-sided to ignore the impact of the latter policy and simply attribute $\mathrm{CO}_{2}$ emissions reduction in that period to WEGTP. Therefore, this paper eliminates Xinjiang, Gansu, Qinghai, Yunnan and other provinces involved in the Great Western Development Strategy, and re-conducts PSM-DID estimation on the processed samples for the purpose of eliminating the impact of the Great Western Development Strategy on the explained variable. From the new regression results, we find the coefficient of interaction item is -0.097 and significant, which is only a gap of 0.014 from the previous result. This shows that the Great Western Development Strategy has little impact on $\mathrm{CO} 2$ emissions, and WEGTP is the main policy reason affecting $\mathrm{CO}_{2}$ emissions.

\subsection{Discussion on mechanisms}

The mechanisms of action of WEGTP on China's energy consumption and $\mathrm{CO}_{2}$ emissions reduction are as follows:

First, the use of natural gas increased greatly. The natural gas consumption in the involved provinces structurally exceeded that in the non-involved provinces. Figure 1 shows that the average consumption of the involved provinces exceeds that of the non-involved provinces, solving the energy shortage problem in the economic development process of central and eastern regions.

Second, an interprovincial structural adjustment mechanism was generated. The natural gas substitution effect and the overuse of natural gas under price control occurred in the importer provinces. Natural gas has the advantages of high thermal efficiency, low price and low emission intensity, encouraging the enterprises in central and eastern energy importer provinces to change their industrial energy from coal to natural gas, thus bringing about a continuous rise in the total energy consumption in the importer provinces.

Third, the low emission property of natural gas is conducive to the reduction of $\mathrm{CO}_{2}$ emissions in central and eastern importer provinces, but due to the rapid economic growth in the eastern region, the effect of total energy consumption increase and the $\mathrm{CO}_{2}$ emissions reduction effect brought by energy structure changes neutralized each other, so that the reduction effect of total $\mathrm{CO}_{2}$ emissions was not obvious.

Fourth, the energy exporter provinces of WEGTP show a trend of increased ECER pressure and increasingly insignificant energy consumption. Because natural gas has a more significant substitution effect on high pollution energy, under the ECER policy constraints of local governments, reducing $\mathrm{CO}_{2}$ emission intensity brought by reducing coal consumption should be more obvious.

Table 5 Robustness test 


\begin{tabular}{lllll} 
Variables & \multicolumn{2}{l}{$\begin{array}{l}\text { Randomness of policy } \\
\text { intervention time }\end{array}$} & $\begin{array}{l}\text { The spillover of } \\
\text { policy effects }\end{array}$ & $\begin{array}{l}\text { Uniqueness of policy } \\
\text { implementation }\end{array}$ \\
\hline & T1=2001 & T2=2000 & & GWDS policy \\
\hline & -0.021 & 0.007 & 0.043 & $-0.097^{* \star *}$ \\
& $(-0.330)$ & $(0.170)$ & $(1.02)$ & $(-2.940)$ \\
\hline F-test & 98.330 & 121.730 & 122.080 & 109.570 \\
& $(0.000)$ & $(0.000)$ & $(0.000)$ & $(0.000)$ \\
\hline Control & Controled & Controled & Controled & Controled \\
variables & & & & 0.903 \\
\hline Adjust $R^{2}$ & 0.873 & 0.868 & 0.868 & 300 \\
\hline$N$ & 459 & 459 & 459 &
\end{tabular}

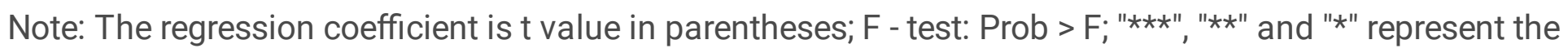
significance level of $1 \%, 5 \%$ and $10 \%$ respectively.

\section{Conclusion And Revelation}

This paper studies the impacts of WEGTP on $\mathrm{CO}_{2}$ emissions through the PSM-DID model, using $\mathrm{CO}_{2}$ emission as the explained variable. The results suggest that WEGTP reduced $\mathrm{CO}_{2}$ emissions. To be specific, the opening of WEGTP transmitted natural gas from the western region to the eastern provinces, providing clean energy for economic and social development, improving energy structure, and reducing $\mathrm{CO}_{2}$ emissions in the provinces along the line. This paper also discusses the heterogeneity of the energy exporter provinces and the energy importer provinces. The results once again demonstrate the ECER effect. This paper believes that the significance of WEGTP is not only quantitatively reducing $\mathrm{CO}_{2}$ emissions, but also proving a long-term development mode of ECER, and accumulating more experience conducive to reducing the environmental pollution. The following suggestions are therefore put forward:

First, promote the widespread use of natural gas and advance the low-carbon substitution of primary energy structure. Before clean energy reaches a low enough cost of social popularization and technological maturity, traditional fossil fuels can be gradually replaced by natural gas to achieve the first stage of energy conservation and emissions reduction. For low-income countries, natural gas substitution is a lower-cost energy conservation program than the popularization of clean energy. For China, at this stage, it is still necessary to figure out the price mechanism of natural gas consumption, actively promote industrial restructuring, and meet the objective requirements of high-quality development with the actual results of ECER.

Second, strengthen industrial restructuring and energy structure optimization. WEGTP provides clean energy for the provinces along the line, improves energy structure, and promotes industrial restructuring, 
thus reducing $\mathrm{CO}_{2}$ emissions. Therefore, it is necessary to fully implement emissions reduction indicators, promote the use of clean energy such as biogas and natural gas, develop renewable energy such as wind energy and solar energy, and improve the energy structure; step up efforts to eliminate industries with backward structures and capacities, control high energy consumption and develop industries with low energy consumption and low pollution, and adjust the industrial structure.

Third, increase investment in technology and encourage technological innovation. Technological innovation also has a considerable impact on energy conservation and emissions reduction, and it has been proved that the increasing use of energy-saving devices and products by people with technological progress can reduce $\mathrm{CO}_{2}$ emissions. Therefore, we should increase investment in research and development and encourage scientific and technological innovation; promote and apply new technologies, new equipment, and new products of ECER; reduce environmental pollution from the two aspects of energy conservation and emissions reduction.

\section{Declarations}

Acknowledgement The authors would like to express gratitude to the editor and anonymous referees for their insightful and constructive comments. The work is supported by the Science Research Key Project of Wenhua College(N0.2020Y13).

Authors' Contributions LUAN and CUI developed the idea of the study; LUAN had the major contributions in writing the manuscript; ZHANG and XIE participated in its design and coordination, XIE helped to draft the manuscript. ZHANG contributed to the acquisition and interpretation of data. YAN and CUI provided critical review and substantially revised the manuscript. All authors read and approved the final manuscript.

Funding This research received no external funding.

Data availability All the research data or analysed during this study are included in this manuscript.

Declarations This study was purely registry based, as no human participants were recruited or included in experiments.

The authors declare no competing interests.

Ethical approval Ethics approval is not required for this paper.

Consent to participate Not applicable.

Consent to publish All authors have read the manuscript and approve of its submission to Environmental Science and Pollution Research.

Conflict of interest The authors declare that they have no conflicts of interest. 


\section{References}

ASHENFELTERO, CARDD(1985) Using the longitudinal structure of earnings to estimate the effect of training programs囚Review of Economics and Statistics $67(4): 648-660$

Cui HR, Wang HR, Zhao QZ(2019) Analysis of influencing factors of regional carbon emissions in China based on dynamic panel model. Science and Technology Management Research 12.034.

Dai R, Cao JH(2015) Evaluation of the carbon reduction effect of China's first "low-carbon pilot" policy Based on DID estimation of five provinces and eight cities. Science and Technology Management Research 12.011.

David Card and Alan B. Krueger(1994)Minimum Wages and Employment:A Case Study of the Fastfood Industry in New Jersey and Pennsylvania. American Economic Review 84(4) :772-793囚 1994:

DIETZTDietztd囚ROSAEA(1994) Rethinking the environmental impacts of population囚affluence and technology. Human Ecology Review 1(2) : 277ه300

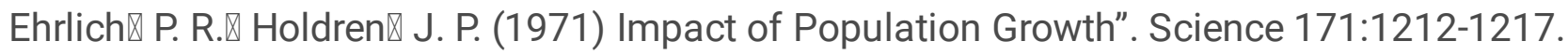

He Y, Fu F, Liao N. (2021) Exploring the path of carbon emissions reduction in China's industrial sector through energy efficiency enhancement induced by R\&D investment. Energy 225: 120208.

Liang RB, Xi PH (2016) Heterogeneous impact of rail transit on air pollution: An empirical study based on RDID method. China Industrial Economics 03:83-98.

Lin BQ, Jiang ZJ (2009) Environmental Kuznets curve prediction of Carbon dioxide in China and analysis of influencing factors. Management World 04.

Liu GW, Zhao T (2012) Dynamic effect analysis of factors influencing carbon emission intensity in China. Resources Science 34(11):2016-2114.

Liu X, Yang X, Guo R. (2020) Regional differences in fossil energy-related carbon emissions in China's eight economic regions: Based on the Theil index and PLS-VIP method. Sustainability, 12(7): 2576.

Pang J, Wu J, Ma Z, Liang LN, Zhang TT (2015) Air pollution reduction effect of replacing coal-fired central heating with natural gas in Chinese cities. China Environmental Science 35(01):55-61.

Shuai C\Shen L囚Jiao L囚et al.(2017) Identifying key impact factors on carbon emission: Evidences from panel and timeđseries data of 125 countries from 1990 to 2011. Applied Energy 187:310-325.

Song DY, Lu ZB (2009) Study on the decomposition and periodic fluctuation of influencing factors of Carbon emission in China. China Population, Resources and Environment 19(03):18-24. 
Sun ZR, Zhou DQ (2013) Driving factors of carbon emission in China based on The Decomposition of Divisia Index. Economic Perspectives 5:54-61.

Tang G, Lin M, Xu Y, et al. (2021) Impact of rating and praise campaigns on local government environmental governance efficiency: Evidence from the campaign of establishment of national sanitary cities in China. Plos one 16(6): e0253703.

Tang Y, Liang RB (2018) Can alternative energy policies improve air quality - with discussion on the impact of energy pricing mechanism. China Population, Resources and Environment 28(06):80-92.

Tian ZH, Yang ZL, Cai RX (2015) Analysis of carbon emission from energy consumption in Guangdong Province and study on influencing factors of carbon emission. China Environmental Science 35(6):18851891.

Xi PH, Liang RB (2015) Influence of oil price change on air pollution: using motor vehicle as pathway. China Industrial Economics 10:110-114.

Xu SC, Long RY (2015) Efficiency measurement and influencing factors of energy and carbon emissions in China 29(3):74-78.

Xue J, Luo H, LYU LH, Zhao J, Wang X (2012) Emission characteristics and correlation of major air pollutants and greenhouse gases in China. Resources Science 34(08):1452-1460.

Wu J, Cui C, Mei X, et al. (2021) Migration of manufacturing industries and transfer of carbon emissions embodied in trade: empirical evidence from China and Thailand. Environmental Science and Pollution Research 6: 1-13.

Zhang QY, Zhang YL, Pan BB (2019) Analysis on the influence factors of China's economic growth and carbon emission during the 40 years of reform and opening up. Journal of Arid Land Resources and Environment 10-009-05.

\section{Figures}




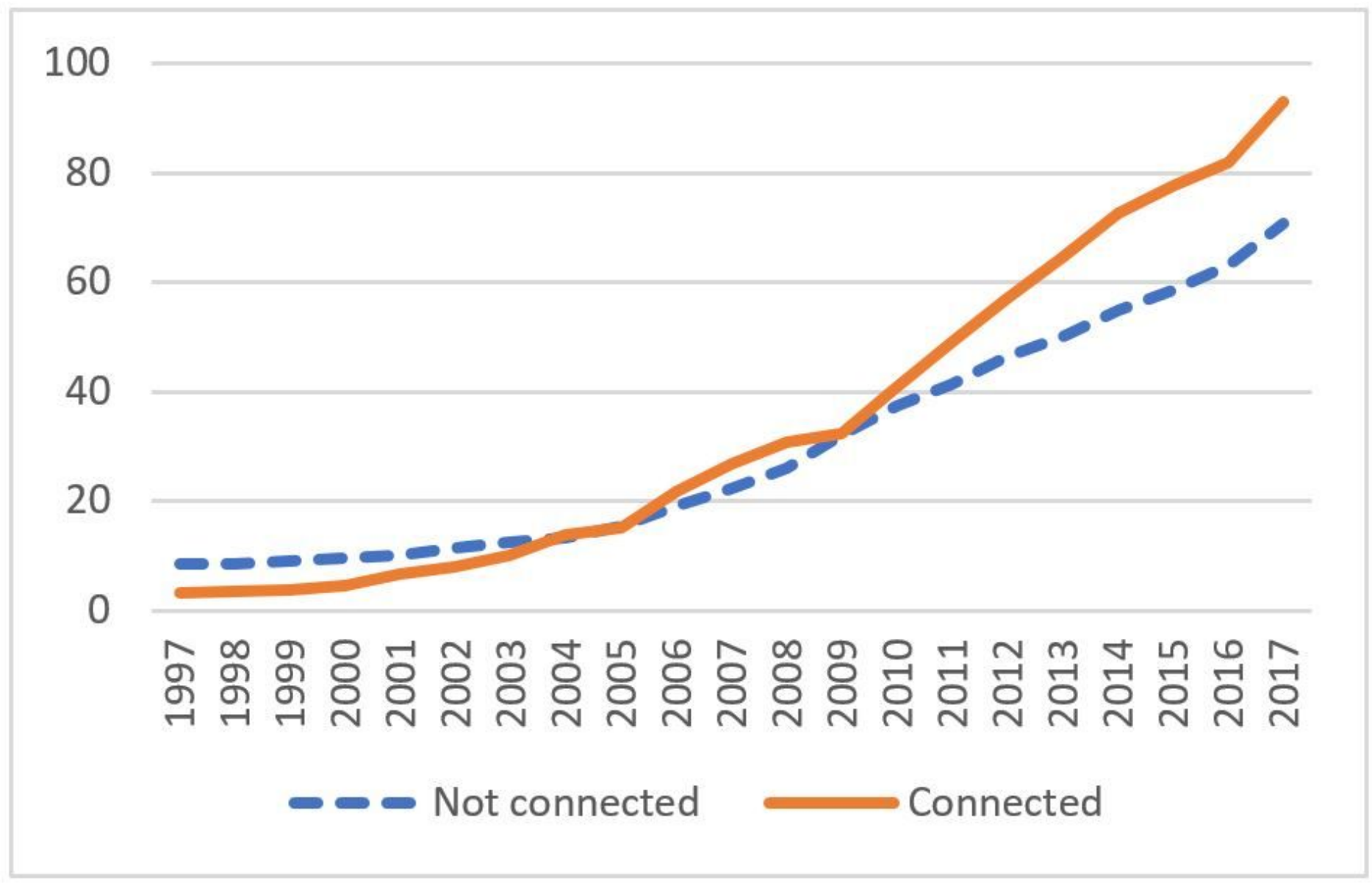

Figure 1

Provincial comparison of average annual gas consumption 


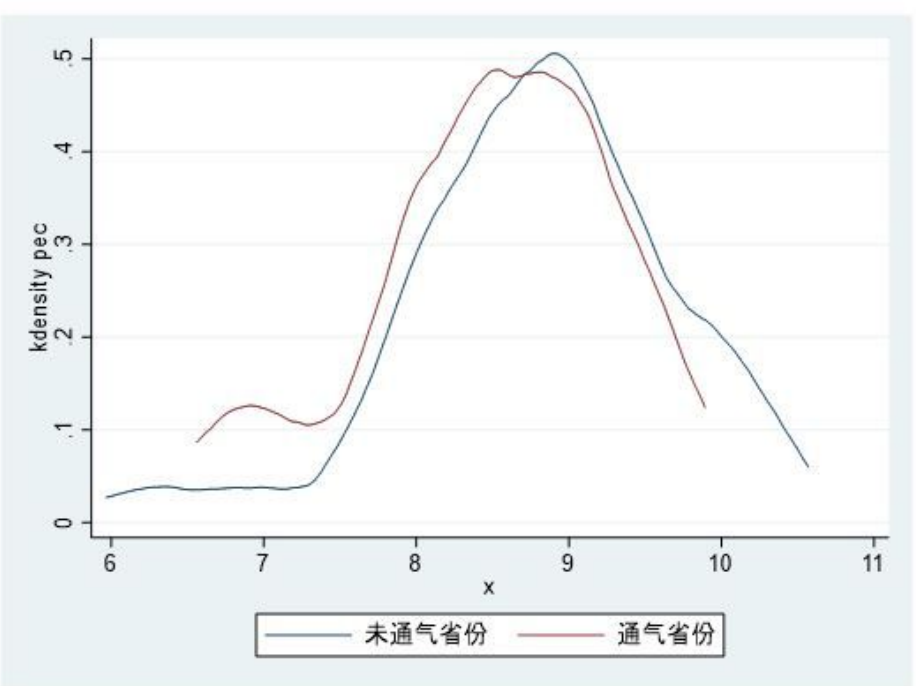

(a) Before match

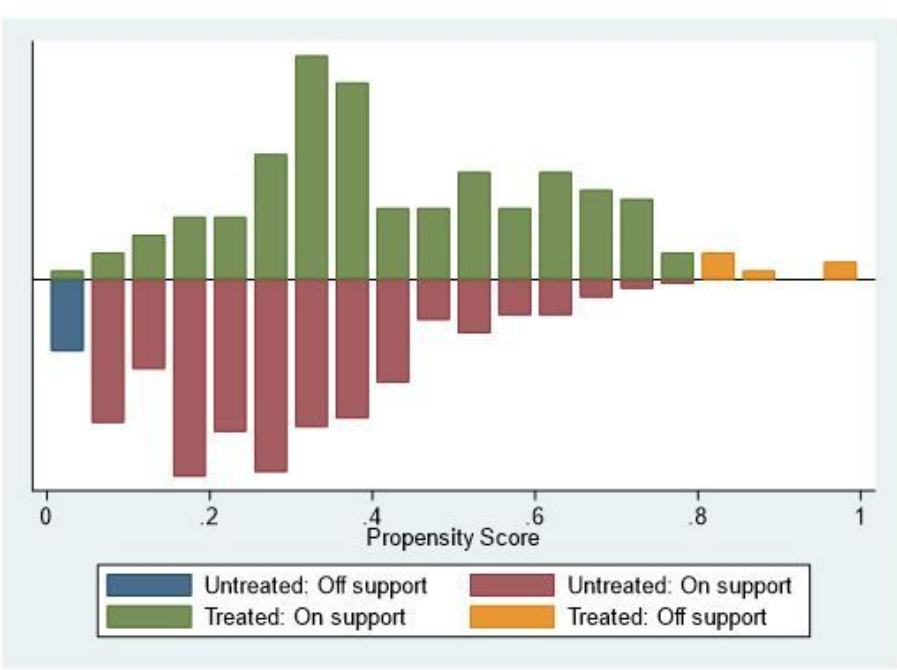

(c) Common value range of PSM

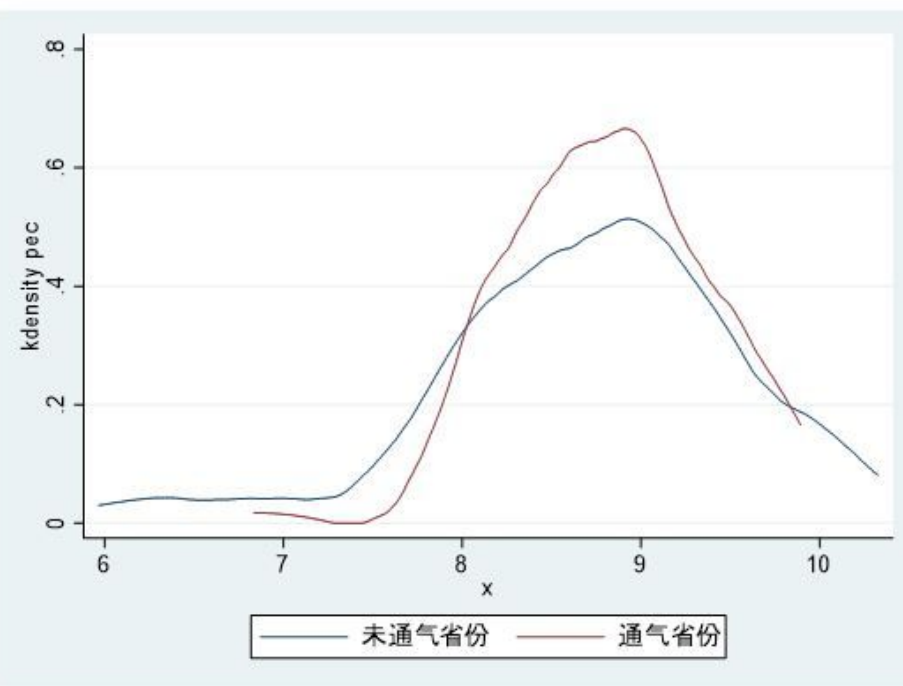

(b) After matched

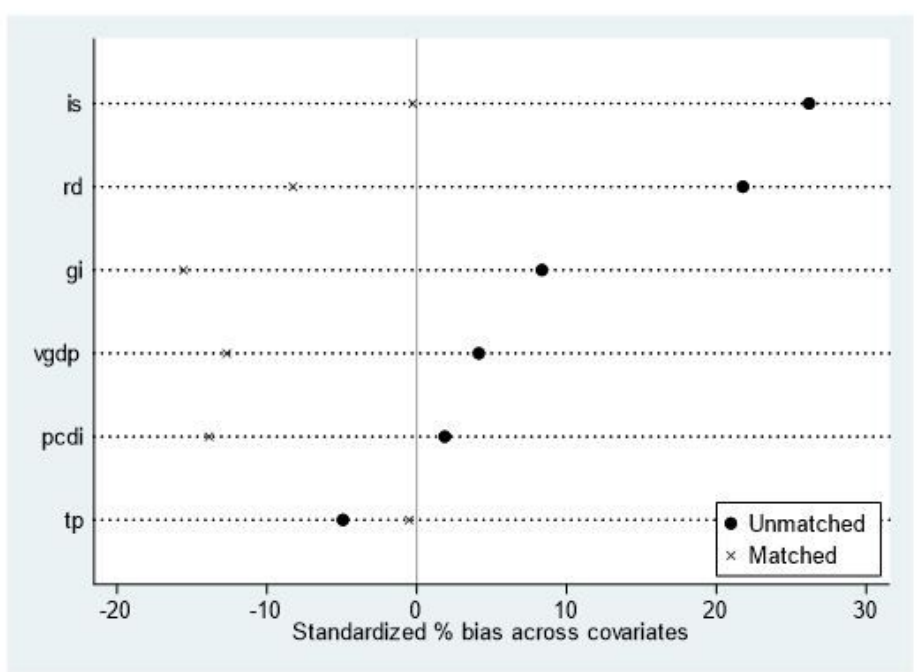

(d) Scatter diagram of variables

\section{Figure 2}

Kernal density distribution comparison and balance test of PSM 